\title{
Preoperative C-reactive protein to albumin ratio and oral health in oral squamous cell carcinoma patients
}

Arvi Keinänen ${ }^{{ }^{*}}$, Johanna Uittamo ${ }^{1}$, Magdalena Marinescu-Gava ${ }^{1,2,3}$, Satu Kainulainen ${ }^{1}$ and Johanna Snäll ${ }^{1}$

\begin{abstract}
Background: The C-reactive protein to albumin (CRP/alb) ratio can predict early survival of a hospitalized patient. We evaluated factors that influence the preoperative CRP/alb ratio in oral squamous cell carcinoma (OSCC) patients and in particular clarified the role of oral health to this ratio.

Materials and methods: Data from surgically treated OSCC patients were collected retrospectively. The outcome variables were preoperative CRP/alb ratio, CRP level, and alb level. The studied predictors were total number of teeth, periodontal stability, marginal bone loss, tumour stage, T-class, lymph node status, and site. The statistical significance of age, sex, comorbidity combination of age and disease history (Charlson Comorbidity Index [CCI]), smoking, and alcohol history for outcome variables were evaluated. Patient 3-month mortality and occurrence of postoperative infections were recorded.
\end{abstract}

Results: A total of 159 patients were included in the study. The early mortality was 3.8\%. CRP/alb was higher in these patients than in those who survived. The only independent variables for CRP/alb changes were CCl and heavy alcohol use. The CRP/alb ratio was significantly lower in non-heavy alcohol users (odds ratio [OR] 0.114, 95\% confidence interval [CI] 0.024-0.541; adjusted $p=0.006$ ) than in other patients. Patients with CCI 0-1 were more likely to have a lower $\mathrm{CRP} / \mathrm{alb}$ ratio than patients with $\mathrm{CCl} \geq 5$ (OR 0.033, 95\% Cl 0.004-0.284; adjusted $p=0.002)$. In addition, high CRP/alb ratio associated with postoperative infections $(p=0.026)$.

Conclusions: The CRP/alb ratio was high in OSCC patients with combined comorbities of age and disease history and in patients with heavy alcohol use. Oral health or tumour-related variables did not independently affect the CRP/ alb ratio. The CRP/alb ratio appears suitable for prediction of OSCC patient early survival.

Keywords: Oral cancer, CRP/albumin ratio, Oral health, Cancer survival

\section{Background}

The predominant type of oral cancer is oral squamous cell carcinoma (OSCC), which comprises $90 \%$ of all oral carcinomas [1]. The main risk factors for the development of OSCC are alcohol consumption and tobacco smoking [2]. The survival rate of patients with OSCC

\footnotetext{
*Correspondence: keinanen.arvi@gmail.com

${ }^{1}$ Department of Oral and Maxillofacial Diseases, University of Helsinki and Helsinki University Hospital, P.O. Box 220, 00029 Helsinki, Finland Full list of author information is available at the end of the article
}

depends on many factors, such as age, gender, diagnosis time, socioeconomic background, and tumour, node, and metastasis (TNM) classification [3]. In particular, the OSCC survival rate is highly dependent on cancer staging [4]. Disease-specific survival beyond 3 years is approximately $70 \%$ in patients with stage-I tumours, whereas in stage III/IV OSCCs only $60 \%$ patients survive beyond 3 years [4].

It has been suggested that in a malignant tumour, inflammatory cells act as early intrinsic defence 
mechanisms to resist the tumour. However, chronic inflammation results in tumour angiogenesis and DNA damage, which both increase C-reactive protein (CRP) levels $[5,6]$. OSCC patients with larger tumours and more advanced tumour stages have reduced overall survival when increased CRP levels are present $[7,8]$. Thus, the CRP level is considered to increase the prognostic power in OSCC patients.

In addition to CRP, the chronic phase protein albumin (alb) is an indicator of the patient's nutritional and inflammatory status $[9,10]$. Systemic inflammation, followed by a decrease in alb level, results in poor performance, weight loss, and nutritional deficiency, all of which negatively affect the prognosis of patients with cancer [11]. Serum alb levels are lower in patients with oral pre-malignancy and oral malignancy compared with healthy individuals. In addition, increased salivary alb levels have been observed in patients with oral premalignancy and oral malignancy compared with healthy individuals [12].

CRP is an acute-phase infective and inflammatory process protein. An increase in CRP production and diminished alb as a negative acute-phase protein are most often associated with chronic disease [13, 14]. The ratio of CRP/alb correlates particularly well with the modified early warning score (MEWS), which is associated with a poorer outcome in many systemic diseases [14]. Fairclough et al., 2009 observed in a follow-up study of 300 patients that the CRP/alb ratio was generally better than MEWS as a predictor of death in younger patients [14]. The CRP/alb ratio is a novel inflammation-based prognostic score and has shown outstanding prognostic value in tumours such as those of the liver or lung [15-17]. The $\mathrm{CRP} / \mathrm{alb}$ ratio is comparable or even superior to other inflammation-based prognostic scores in predicting prognosis [15-17].

Oral health and particularly the infectious load of periodontitis may have systemic effects [18]. There are some studies on the associations between oral health and serum alb levels [18-20]. The role of oral microbes is associated with the inflammatory process itself and cancer risk [21], and the relationship between periodontal status and cancer prognosis has been evaluated. The mortality of orodigestive cancers increases according to the severity of periodontitis [22]. Additionally, the periodontal pathogen Porphyromonas gingivalis has been presented as a biomarker for microbe-associated risk of death [22].

The purpose of the present study was to evaluate the factors that influence preoperative CRP and alb levels and particularly the CRP/alb ratio in patients with OSCC. We also focused on the role of oral health. We hypothesized that the CRP/alb ratio differs between OSCC patients.

\section{Materials and methods}

\section{Patient material}

Patient records from the 3-year period between January 2016 and December 2018 at the Head and Neck Centre, Helsinki University Hospital, Helsinki, Finland were evaluated. Our search was based on data from the multidisciplinary head and neck tumour board of Helsinki University Hospital, which covers data of all primary diagnosed OSCC patients.

Data on OSCC patients and tumours, laboratory values, radiological dental status, information on smoking and alcohol consumption habits, and early overall survival were collected retrospectively.

\section{Inclusion and exclusion criteria}

Patients with a primary OSCC diagnosis who received surgical treatment for the malignancy were included. An additional inclusion criterion was the availability of a digital panoramic radiography (DPR) of dentate patients. Patients with additional malignancy, previous head or neck malignancy, previous radiotherapy in the region of head or neck, preoperative acute infection, and missing preoperative CRP or alb values or incomplete information on smoking or alcohol consumption were excluded.

\section{Study design}

The primary outcome variable was CRP/alb ratio before treatment. Additional outcome variables were CRP level $(\mathrm{mg} / \mathrm{l})$ and alb $(\mathrm{g} / \mathrm{l})$ levels before treatment. The lowest value of CRP that could be obtained by laboratory tests was $<3 \mathrm{mg} / \mathrm{l}$.

Predictor variables related to oral health were periodontal stability, marginal bone loss, and number of teeth. Patients were grouped according to number of teeth, which included third molars and excluded dental implants. In assessing periodontal status, unerupted teeth, teeth without sound supragingival tissue remaining (crown affected by caries), and teeth floating in parts of the jaw affected by the tumour were excluded.

Tumour-related predictor variables included prognostic stage group (i.e. cancer severity), tumour size, patient lymph node status, and tumour site. The prognostic stage group was defined according to the Oral Cavity cancers-AJCC 8th Edition into two subgroups (stage 0-II and stage III-IV) [23]. Correspondingly, tumour size was defined according to $\mathrm{T}$ categorization as Tis-2 (Tis, T1, or T2) or T3-4 (T3 or T4). Pathological lymph node status was categorized as N0 and N1 or more.

Explanatory variables were age, gender, smoking, heavy alcohol use, and Charlson Comorbidity Index (CCI) [24], which combines comorbidity for age and disease history. Patients were divided into three CCI groups as follows: $0-1$ points, $2-4$ points, and $\geq 5$ points [24]. Patients were 
stratified by smoking habit into the following two groups: non-smokers (i.e. non-smokers and former smokers who have been in cessation $\geq 5$ years) and current and former smokers (i.e. who have been in cessation $<5$ years) [25]. Alcohol use was determined according to the Finnish Current Care Guidelines consumption limits for heavy alcohol use: $\geq 23$ doses (i.e. $\geq 287.5 \mathrm{~g}$ of alcohol) per week for men and $\geq 12$ doses (i.e. $\geq 150 \mathrm{~g}$ alcohol) per week for women as suggested by Finnish working group [26].

Patients early mortality and occurrence of postoperative infections during the first three months were recorded. Associations between early mortality and postoperative infections and the CRP/alb ratio were reported.

\section{Radiological analyses for periodontal status}

Dental panoramic radiograph images (Instrumentarium Dental $^{\mathrm{TM}}$ Orthopantomograph ${ }^{\mathrm{TM}}$ OP200 or Orthopantomograph ${ }^{\circledR}$ OP300) were reviewed by an oral radiologist (M.M.G.) twice at 6-month intervals. For discordant results, the more severe status was used for the study.

Periodontal status was evaluated for periodontal stability and marginal bone loss. Stability was defined according to alveolar marginal crest and described as stable if a corticated alveolar marginal crest was radiologically identifiable (i.e. presence of a corticated crestal lamina dura). When present, marginal bone loss was classified as not present, mild, moderate, or severe [27]. Marginal bone loss was determined by tertile as follows: maximum bone loss extending to cervical third (mild), maximum bone loss extending to the middle third (moderate), or maximum bone loss extending to the apical third (severe)
(Fig. 1). Edentulous patients were included as patients with periodontal stability without marginal bone loss.

\section{Statistical analysis}

Associations between patient cancer severity status, clinical data, periodontal status, early death, postoperative infection and CRP, alb and CRP/alb ratio were assessed with the Chi-squared test, Fisher's exact test, and logistic regression analysis based on median values of the population. Hosmer and Lemeshow goodness-of-fit test was used to assess logistic regression analyses. Before conducting multiple logistic regression analyses, Cramer's V test was used to detect possible multicollinearity of categorical explanatory variables. The significance level was set at 0.05. SPSS 25.0 (IBM Corp, Armonk, NY) was used for statistical analyses.

\section{Ethical approval}

The study was approved by the Internal Review Board of the Head and Neck Centre, Helsinki University Central Hospital, Finland (HUS/66/2018).

\section{Results \\ Patient material}

From a total of 305 evaluated patients, 159 OSCC patients who received surgical treatment for primary tumour were included in the final analyses (Fig. 2). In all, 87 patients received microvascular reconstruction in addition to tumour resection (Fig. 3) and 99 patients were given additional chemoradiotherapy. All patients received perioperative antibiotic medication, which was continued as needed postoperatively according to

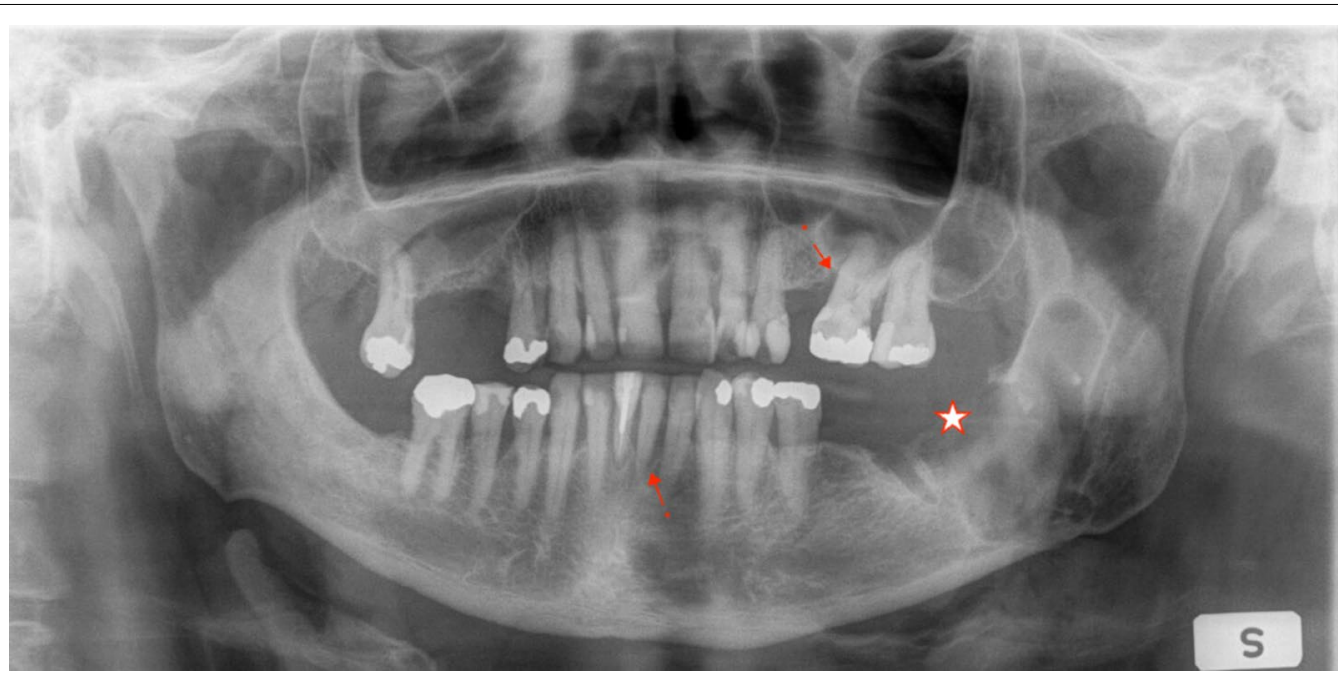

Fig. 1 Panoramic tomography of a patient with missing teeth and periodontal instability, with severe marginal bone loss (up to apical third of the roots, marked with *). On the left there is also tumour-induced bone destruction (star), which in this case does not involve a dentate area of the mandible. 


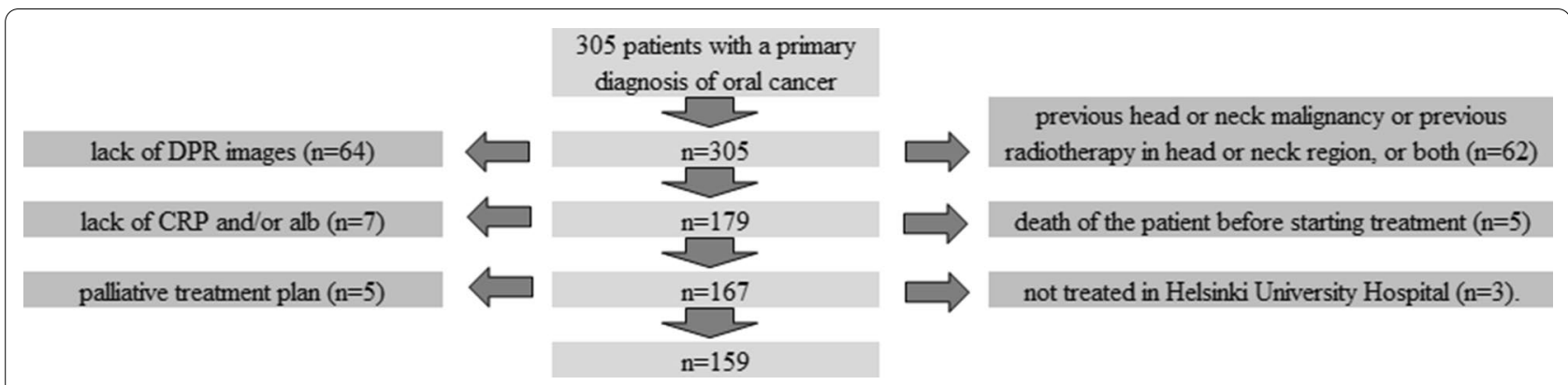

Fig. 2 In all remaining 159 patients, requisite data on smoking and alcohol consumption were available. Thus, 159 patients were included in the final analyses.

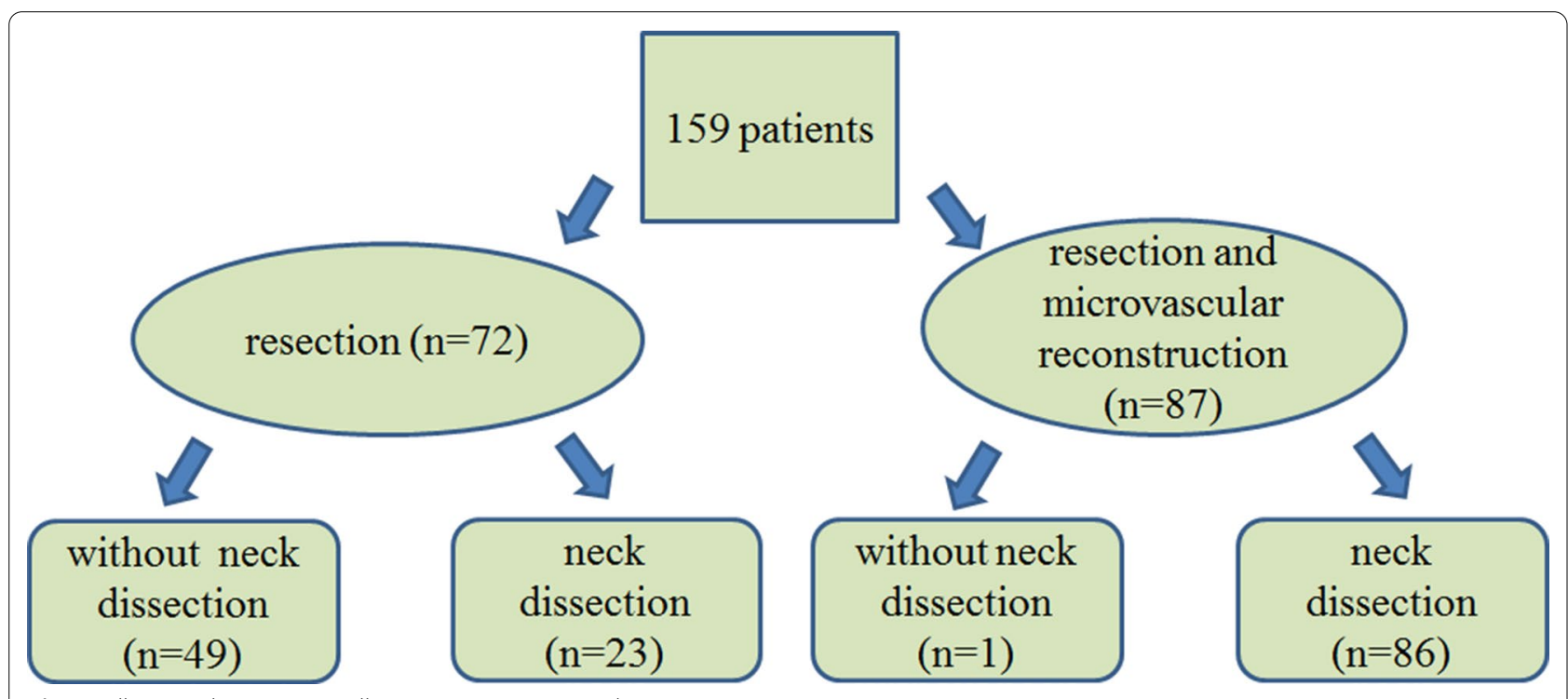

Fig. 3 All 159 oral squamous cell carcinoma patients underwent tumour resection.

the type of procedure. Most patients were male (51.6\%). Median age was 66.0 years. Most patients were nonsmokers $(50.3 \%)$ and did not have a history of heavy alcohol use (82.4\%). The most common primary tumour site was tongue (44.0\%), followed by gingiva or palate (34.0\%), floor of the mouth (15.7\%), and cheek (6.3\%). Median values for the studied laboratory variables were the following: CRP $<3 \mathrm{mg} / \mathrm{l}$, alb $38.00 \mathrm{~g} / \mathrm{l}$, and CRP/alb $0.05(\mathrm{mg} / \mathrm{l}) /(\mathrm{g} / \mathrm{l})($ Table 1$)$.

In all, 6 patients died during the first postoperative three months $(3.8 \%)$. The cause of death was cardiovascular in 3 patients, respiratory infection or respiratory complication in 2 patients and 1 patient died while receiving palliative cancer care. Of the deceased patients, three had T4, two had T3 and one had T2 tumour. Four of these six patients received microvascular reconstruction. The CRP/alb ratio was higher in these patients compared to surviving patients (Table 2).
In all, 25 of 159 patients (15.7\%) had infections during the first postoperative three months. In eleven patients infections were associated with surgical site, nine patients had pneumonia, two had urinary tract infections, one had salivary gland infection, one had infection associated with tracheostomy and one had infection associated with a gastrostomy tube. Patients with higher CRP/alb ratio were significantly more likely to have postoperative infections than patients with lower CRP/alb ratio $(p=0.026)$ (Table 2).

Smokers had significantly higher CRP levels ( $p=$ $0.036)$ and higher alb levels $(p=0.026)$ than non-smokers (Table 3). Patients with a history of heavy alcohol use had significantly higher CRP levels $(p=0.001)$ and a higher CRP/alb ratio $(p=0.016)$ compared with the other patients. Patients with a higher CCI score more often had lower alb levels $(p<0.001)$ and a higher CRP/ alb ratio $(p<0.001)$. Associations between explanatory variables and CRP/alb ratio are shown in Table 4. 
Table 1 Descriptive statistics of 159 oral carcinoma patients.

\begin{tabular}{|c|c|c|c|c|c|c|c|}
\hline & & \multirow[t]{2}{*}{ No. of patients } & \multirow[t]{2}{*}{$\%$} & \multirow[t]{2}{*}{ t/9 } & \multicolumn{2}{|l|}{ Gender } & \multirow[t]{2}{*}{$p$ value } \\
\hline & & & & & Male (\%) & Female (\%) & \\
\hline \multicolumn{8}{|l|}{ Age (years) } \\
\hline Range & $23-96$ & & & & & & \\
\hline Mean & 66.83 & & & & & & \\
\hline Median & 66.00 & & & & & & \\
\hline$<66$ & & 77 & 48.4 & $48 / 29$ & 58.5 & 37.7 & \\
\hline$\geq 66$ & & 82 & 51.6 & $34 / 48$ & 41.5 & 62.3 & 0.011 \\
\hline \multicolumn{8}{|l|}{ Gender } \\
\hline Male & & 82 & 51.6 & & & & \\
\hline Female & & 77 & 48.4 & & & & \\
\hline \multicolumn{8}{|l|}{ Smoking } \\
\hline Non-smoker & & 80 & 50.3 & $36 / 44$ & 43.9 & 57.1 & \\
\hline Current Smoker & & 79 & 49.7 & $46 / 33$ & 56.1 & 42.9 & 0.113 \\
\hline \multicolumn{8}{|l|}{ Heavy alcohol use } \\
\hline No & & 131 & 82.4 & $65 / 66$ & 79.3 & 85.7 & \\
\hline Yes & & 28 & 17.6 & $17 / 11$ & 20.7 & 14.3 & 0.306 \\
\hline \multicolumn{8}{|l|}{ Site } \\
\hline Tongue & & 70 & 44.0 & $35 / 35$ & 42.7 & 45.5 & \\
\hline Gum or palate & & 54 & 34.0 & $28 / 26$ & 34.1 & 33.8 & \\
\hline Floor of the mouth & & 25 & 15.7 & $15 / 10$ & 18.3 & 13.0 & \\
\hline Cheek & & 10 & 6.3 & $4 / 6$ & 4.9 & 7.8 & 0.734 \\
\hline \multicolumn{8}{|l|}{ Periodontal stability } \\
\hline Present & & 77 & 48.4 & $32 / 45$ & 39.0 & 58.4 & \\
\hline Not present & & 82 & 51.6 & $50 / 32$ & 50.0 & 41.6 & 0.017 \\
\hline \multicolumn{8}{|l|}{ Marginal bone loss } \\
\hline Not present & & 23 & 14.6 & $11 / 12$ & 13.6 & 15.6 & \\
\hline Mild & & 58 & 36.7 & $29 / 29$ & 35.8 & 37.7 & \\
\hline Moderate & & 57 & 36.1 & $28 / 29$ & 34.6 & 37.7 & \\
\hline Severe & & 20 & 12.7 & $13 / 7$ & 16.0 & 9.1 & 0.636 \\
\hline \multicolumn{8}{|l|}{ Total number of teeth } \\
\hline Range & $0-32$ & & & & & & \\
\hline Mean & 19.73 & & & & & & \\
\hline Median & 23.00 & & & & & & \\
\hline 0 & & 16 & 10.1 & $7 / 9$ & 8.5 & 11.7 & \\
\hline $1-12$ & & 16 & 10.1 & $7 / 9$ & 8.5 & 11.7 & \\
\hline $13-24$ & & 64 & 40.3 & $32 / 32$ & 39.0 & 41.6 & \\
\hline $25-32$ & & 63 & 39.6 & $36 / 27$ & 43.9 & 35.1 & 0.655 \\
\hline \multicolumn{8}{|c|}{ Charlson Comorbidity Index } \\
\hline $0-1$ & & 32 & 20.1 & $21 / 11$ & 25.6 & 14.3 & \\
\hline $2-4$ & & 106 & 66.7 & $53 / 53$ & 64.6 & 68.8 & \\
\hline$\geq 5$ & & 21 & 13.2 & $8 / 13$ & 9.8 & 16.9 & 0.130 \\
\hline
\end{tabular}

Statistically significant values are in bold

Primary tumour sites differed significantly when considering alb levels $(p=0.027)$ (Table 5). Patients with floor of the mouth tumours had the highest alb levels compared with other regions. T-class was significantly associated with CRP levels $(p=0.030)$. Patients with larger tumours more often had higher CRP than patients with less extensive tumours. Differences were also significant between total number of teeth and CRP/alb ratio $(p=0.009)$ (Table 6). Edentulous patients and patients 
Table 2 Early postoperative mortality, postoperative infections and CRP/alb ratio in oral squamous cell carcinoma patients

\begin{tabular}{|c|c|c|c|c|c|c|c|c|c|}
\hline & \multirow[t]{3}{*}{ Min } & \multirow[t]{3}{*}{ Max } & \multirow[t]{3}{*}{ Mean } & \multirow[t]{3}{*}{ Median } & \multicolumn{5}{|l|}{ CRP/alb } \\
\hline & & & & & \multicolumn{2}{|l|}{$\leq 0.05$} & \multicolumn{2}{|l|}{$0.05<$} & \multirow[t]{2}{*}{$p$ value } \\
\hline & & & & & n (of 41) & $\%$ & n (of 118) & $\%$ & \\
\hline \multicolumn{10}{|l|}{ Early death } \\
\hline No $(n=153)$ & 0.04 & 1.73 & 0.16 & 0.05 & 40 & 26.1 & 113 & 73.9 & \\
\hline Yes $(n=6)$ & 0.05 & 0.97 & 0.32 & 0.19 & 1 & 16.7 & 5 & 83.3 & $>0.999$ \\
\hline \multicolumn{10}{|c|}{ Postoperative infection } \\
\hline No $(n=134)$ & 0.04 & 1.73 & 0.14 & 0.05 & 39 & 29.1 & 95 & 70.9 & \\
\hline Yes $(n=25)$ & 0.05 & 1.71 & 0.31 & 0.09 & 2 & 8.0 & 23 & 92.0 & 0.027 \\
\hline
\end{tabular}

Statistically significant values are in bold

Table 3 Association between the laboratory tests and patient data in 159 oral carcinoma patients

\begin{tabular}{|c|c|c|c|c|c|c|c|c|c|c|}
\hline & \multicolumn{4}{|l|}{ CRP } & \multirow[b]{3}{*}{$p$ value } & \multicolumn{4}{|l|}{$\mathrm{alb}$} & \multirow[b]{3}{*}{$p$ value } \\
\hline & \multicolumn{2}{|l|}{$<3$} & \multicolumn{2}{|l|}{$3 \leq$} & & \multicolumn{2}{|l|}{$\leq 38$} & \multicolumn{2}{|l|}{$38<$} & \\
\hline & n (of 96) & $\%$ & n (of 63) & $\%$ & & n (of 83) & $\%$ & n (of 76) & $\%$ & \\
\hline \multicolumn{11}{|l|}{ Age (years) } \\
\hline$<66$ & 44 & 57.1 & 33 & 42.9 & & 34 & 44.2 & 43 & 55.8 & \\
\hline$\geq 66$ & 52 & 63.4 & 30 & 36.6 & 0.517 & 49 & 59.8 & 33 & 40.2 & 0.057 \\
\hline \multicolumn{11}{|l|}{ Gender } \\
\hline Male & 48 & 58.5 & 34 & 41.5 & & 41 & 50.0 & 41 & 50.0 & \\
\hline Female & 48 & 62.3 & 29 & 37.7 & 0.631 & 42 & 54.5 & 35 & 45.5 & 0.634 \\
\hline \multicolumn{11}{|l|}{ Smoking } \\
\hline non-smoker & 68.8 & 25 & 31.3 & & & 49 & 61.3 & 31 & 38.8 & \\
\hline current smoker & 51.9 & 38 & 48.1 & 0.036 & & 34 & 43.0 & 45 & 57.0 & 0.026 \\
\hline \multicolumn{11}{|c|}{ Heavy alcohol use } \\
\hline No & 87 & 66.4 & 44 & 33.6 & & 67 & 51.1 & 64 & 48.9 & \\
\hline Yes & 9 & 32.1 & 19 & 67.9 & 0.001 & 16 & 57.1 & 12 & 42.9 & 0.678 \\
\hline \multicolumn{11}{|c|}{ Charlson Comorbidity Index } \\
\hline $0-1$ & 23 & 71.9 & 9 & 28.1 & & 7 & 21.9 & 25 & 78.1 & \\
\hline $2-4$ & 64 & 60.4 & 42 & 39.6 & & 61 & 57.5 & 45 & 42.5 & \\
\hline$\geq 5$ & 9 & 42.9 & 12 & 57.1 & 0.123 & 15 & 71.4 & 6 & 28.6 & $<0.001$ \\
\hline
\end{tabular}

Statistically significant values are in bold

with 13-24 teeth more often had a lower CRP/alb ratio than other patients.

Multiple logistic regression analysis included heavy alcohol use and CCI for CRP/alb ratio (Table 7). The $\mathrm{CRP} / \mathrm{alb}$ ratio was significantly lower in patients with no history of heavy alcohol use (odds ratio [OR] 0.114, 95\% confidence interval [CI] 0.024-0.541; adjusted $p=0.006$ ) than in patients with history of heavy alcohol use. In addition, patients with CCI $0-1$ were more likely to have lower CRP/alb ratio than patients with $\mathrm{CCI} \geq 5$ (OR 0.033, 95\% CI 0.004-0.284; adjusted $p=0.002$ ).

\section{Discussion}

We evaluated the factors that influence preoperative CRP and alb levels and the CRP/alb ratio in OSCC patients. We also evaluated the role of oral health. We hypothesized that the CRP/alb ratio differs between OSCC patients, which was confirmed in this study. Although numerous factors were associated with CRP and alb and $\mathrm{CRP} / \mathrm{alb}$, heavy alcohol use, high CCI were found to be the only independent variables for CRP/alb increase. In addition, we found statistically significant association between high CRP/alb ratio and postoperative infections. $\mathrm{CRP} / \mathrm{alb}$ scores in OSCC patients have been considered as promising predictive markers for patients with OSCC in addition to tumour staging [28]. A previous study on OSCC patients treated with concomitant 
Table 4 Association between the laboratory tests and patient data in 159 oral carcinoma patients

\begin{tabular}{|c|c|c|c|c|c|}
\hline & \multicolumn{4}{|l|}{ CRP/alb } & \multirow[b]{3}{*}{$p$ value } \\
\hline & \multicolumn{2}{|l|}{$\leq 0.05$} & \multicolumn{2}{|l|}{$0.05<$} & \\
\hline & $\mathrm{n}$ (of 41) & $\%$ & n (of 118) & $\%$ & \\
\hline \multicolumn{6}{|l|}{ Age (years) } \\
\hline$<66$ & 25 & 32.5 & 52 & 67.5 & \\
\hline$\geq 66$ & 16 & 19.5 & 66 & 80.5 & 0.071 \\
\hline \multicolumn{6}{|l|}{ Gender } \\
\hline Male & 23 & 28.0 & 59 & 72.0 & \\
\hline Female & 18 & 23.4 & 59 & 76.6 & 0.587 \\
\hline \multicolumn{6}{|l|}{ Smoking } \\
\hline Non-smoker & 21.3 & 63 & 78.8 & & \\
\hline Current smoker & 30.4 & 55 & 67.6 & 0.208 & \\
\hline \multicolumn{6}{|l|}{ Heavy alcohol use } \\
\hline No & 39 & 29.8 & 92 & 70.2 & \\
\hline Yes & 2 & 7.1 & 26 & 92.9 & 0.016 \\
\hline \multicolumn{6}{|c|}{ Charlson Comorbidity Index } \\
\hline $0-1$ & 16 & 50.0 & 16 & 50.0 & \\
\hline $2-4$ & 24 & 22.6 & 82 & 77.4 & \\
\hline$\geq 5$ & 1 & 4.8 & 20 & 95.2 & $<0.001$ \\
\hline
\end{tabular}

Statistically significant values are in bold

radio-chemotherapy showed that CRP and alb predicted patient long-term survival [29]. However, even in this selected patient population, only radiotherapy combined with chemotherapy remained significant in multivariate analyses. While early mortality was low in the present population (3.8\%), the CRP/alb ratio was higher in these patients than survivors. Thus, the CRP/ alb ratio seems to be more appropriate for assessing early prognosis of OSCC patients.

Preoperative high-sensitivity-CRP (hs-CRP) to alb ratio has previously shown to predict independently signs of severe infection in nephrolithotomy [30]. The $\mathrm{CRP} / \mathrm{alb}$ ratio predicted postoperative infections also in our data, although hs-CRP was not used. As many as 23 of 25 patients with postop infection had a CRP/alb ratio that exceeded the median of our data. Indeed, in addition to predicting early mortality, CRP/alb appears to be promising for predicting the risk of postoperative infections in oral cancer patients. Further studies should be performed in patient groups where surgical and postoperative care are congruent.

Heavy alcohol use and smoking also increased preoperative CRP, as shown previously [31, 32]. Imhof et al. 2001 found that men's alcohol consumption showed a $\mathrm{U}$-shaped association with mean CRP values. In their study, non-drinkers and heavy drinkers had higher CRP concentrations than moderate drinkers [32]. In this patient population, only 1 out of 28 heavy alcohol users had liver cirrhosis. According to our results, heavy alcohol use is therefore a notable factor that increases CRP levels in OSCC patients. Even if smokers more often had higher CRP than non-smokers, they also had higher alb values. Thus, no effect of smoking was found on the CRP/alb ratio.

Systemic inflammation in cancer patients is considered to relate to prognosis. Various mechanisms are involved in inflammation cascades during OSCC development and progression. Tumour growth, invasion, or both can cause inflammation via necrosis, tumour hypoxia, or local tissue damage [33-35]. Inflammatory cells related to the tumour and tumour cells related to tumorigenic inflammatory cytokines, such as tumour necrosis factor, interleukin (IL) IL-1, IL-6, and vascular endothelial growth factor [33-35] can induce invasion, growth, and tumour metastasis [33-35]. CRP production increases as a response to these stimuli mediators and has been shown worsen inflammatory status and advance progression of the oral cancer $[7,8,36]$. Thus, it is consistent that tumour extent is associated with CRP levels as confirmed in the present study.

Hypoalbuminemia is a prognostic marker of survival in the general population and in many pathological settings, mainly due to malnutrition and inflammation [37, 38]. Our results are consistent with previous findings. Higher CCI was associated with lower alb levels. Smokers in our study had surprisingly higher alb levels compared to nonsmokers. The association between low albumin levels and smoking has been thought to indicate the inflammatory response and degree of vascular changes caused by smoking [39], however, albumin levels are also affected by numerous other factors. In the present study, alb levels were likely to be particularly affected by background diseases in a relatively elderly population, due to which the effect of smoking on alb was not observed in our data. However, it should be noted that a single effect of patient age was not found. Somewhat surprisingly, the number of teeth was also not associated with alb levels.

We chose periodontal stability, marginal bone loss, and total number of teeth as measurements of the level of periodontitis and dental health. Patients that had tooth loss had a significantly higher $\mathrm{CRP} / \mathrm{alb}$ ratio than patients without tooth loss, but the difference was non-significant in multivariate analysis. Thus, even if OSCC patients often require further dental care as shown in the present study, these findings do not affect the CRP/alb ratio.

The frequent findings of periodontitis in our results are worth considering. Stable periodontal status was observed in only half of the patients and marginal bone loss was frequent. Radiotherapy and chemotherapy have 
Table 5 Association between the laboratory tests and predictor variables in 159 oral carcinoma patients.

\begin{tabular}{|c|c|c|c|c|c|c|c|c|c|c|}
\hline & \multicolumn{5}{|l|}{ CRP } & \multicolumn{5}{|l|}{ alb } \\
\hline & \multicolumn{2}{|l|}{$<3$} & \multicolumn{2}{|l|}{$3 \leq$} & \multirow[b]{2}{*}{$p$ value } & \multicolumn{2}{|l|}{$\leq 38$} & \multicolumn{2}{|l|}{$38<$} & \multirow[b]{2}{*}{$p$ Value } \\
\hline & n (of 96) & $\%$ & n (of 63) & $\%$ & & n (of 83) & $\%$ & n (of 76) & $\%$ & \\
\hline \multicolumn{11}{|l|}{ Periodontal stability } \\
\hline present & 52 & 67.5 & 25 & 32.5 & & 41 & 53.2 & 36 & 46.8 & \\
\hline not present & 44 & 53.7 & 38 & 46.3 & 0.078 & 42 & 51.2 & 40 & 48.8 & 0.874 \\
\hline \multicolumn{11}{|l|}{ Marginal bone loss } \\
\hline not present & 15 & 65.2 & 8 & 34.8 & & 12 & 52.2 & 11 & 47.8 & \\
\hline mild & 38 & 65.5 & 20 & 34.5 & & 23 & 39.7 & 35 & 60.3 & \\
\hline moderate & 32 & 56.1 & 25 & 43.9 & & 34 & 59.6 & 23 & 40.4 & \\
\hline Severe & 10 & 50.0 & 10 & 50.0 & 0.547 & 14 & 70.0 & 6 & 30.0 & 0.060 \\
\hline \multicolumn{11}{|l|}{ Total number of teeth } \\
\hline 0 & 9 & 56.3 & 7 & 43.8 & & 10 & 62.5 & 6 & 37.5 & \\
\hline $1-12$ & 9 & 56.3 & 7 & 43.8 & & 8 & 50.0 & 8 & 50.0 & \\
\hline $13-24$ & 36 & 56.3 & 28 & 43.8 & & 39 & 60.9 & 25 & 39.1 & \\
\hline $25-32$ & 42 & 66.7 & 21 & 33.3 & 0.620 & 26 & 41.3 & 37 & 58.7 & 0.129 \\
\hline \multicolumn{11}{|l|}{ Stage } \\
\hline$|-| \mid$ & 54 & 65.1 & 29 & 34.9 & & 42 & 50.6 & 41 & 49.4 & \\
\hline||$|-| V$ & 42 & 55.3 & 34 & 44.7 & 0.256 & 41 & 53.9 & 35 & 46.1 & 0.751 \\
\hline \multicolumn{11}{|l|}{ T-class } \\
\hline Tis-T2 & 67 & 67.0 & 33 & 33.0 & & 49 & 49.0 & 51 & 51.0 & \\
\hline T3-T4 & 29 & 49.2 & 30 & 50.8 & 0.030 & 34 & 57.6 & 25 & 42.4 & 0.327 \\
\hline \multicolumn{11}{|l|}{ Lymph node status } \\
\hline No & 73 & 62.9 & 43 & 37.1 & & 61 & 52.6 & 55 & 47.4 & \\
\hline N1 or more & & & & & & 22 & 51.2 & 21 & 48.8 & 1.000 \\
\hline \multicolumn{11}{|l|}{ Site } \\
\hline Tongue & 45 & 64.3 & 25 & 35.7 & & 38 & 54.3 & 32 & 45.7 & \\
\hline Gum or palate & 30 & 55.6 & 24 & 44.4 & & 34 & 63.0 & 20 & 37.0 & \\
\hline Floor of the mouth & 15 & 60.0 & 10 & 40.0 & & 7 & 28.0 & 18 & 72.0 & \\
\hline Cheek & 6 & 60.0 & 4 & 40.0 & 0.793 & 4 & 40.0 & 6 & 60.0 & 0.027 \\
\hline
\end{tabular}

Statistically significant values are in bold

an impact on oral health and the oral cavity should be as free of infection as possible before these oncological treatments. In addition, surgical procedures for OSCC often extend to tooth-bearing regions of the oral cavity. Thus, an individual treatment plan by dentists and oral and maxillofacial surgeons is appropriate to reduce local infections and address other considerations during OSCC treatment, and to promote further rehabilitation of occlusion and jaw function. Appropriate oral and dental care should be included in the OSCC treatment plan to improve the patient's quality of life.
A larger number of patients with additional data from treatment strategies is required to clarify the clinical relevance of the CRP/alb ratio in specific OSCC patient subgroups. In addition, hs-CRP was not recorded, thus the significance of micro infection burden could not be assessed. An additional limitation is that we estimated periodontal status based on radiological findings alone and cariological status or dental-care habits were not analysed.

In summary, even if a number of factors are associated with the $\mathrm{CRP} / \mathrm{alb}$ ratio in oral cancer patients, only the 
Table 6 Association between the laboratory tests and predictor variables in 159 oral carcinoma patients

\begin{tabular}{|c|c|c|c|c|c|}
\hline & \multicolumn{5}{|l|}{ CRP/alb } \\
\hline & \multicolumn{2}{|l|}{$\leq 0.05$} & \multicolumn{2}{|l|}{$0.05<$} & \multirow[b]{2}{*}{$p$ value } \\
\hline & n (of 41) & $\%$ & n (of 118) & $\%$ & \\
\hline \multicolumn{6}{|l|}{ Periodontal stability } \\
\hline Present & 22 & 28.6 & 55 & 71.4 & \\
\hline Not present & 19 & 23.2 & 63 & 76.8 & 0.472 \\
\hline \multicolumn{6}{|l|}{ Marginalbone loss } \\
\hline Not present & 7 & 30.4 & 16 & 69.6 & \\
\hline Mild & 19 & 32.8 & 39 & 67.2 & \\
\hline Moderate & 12 & 21.1 & 45 & 78.9 & \\
\hline Severe & 2 & 10.0 & 18 & 90.0 & 0.166 \\
\hline \multicolumn{6}{|l|}{ Total number of teeth } \\
\hline 0 & 3 & 18.8 & 13 & 81.3 & \\
\hline $1-12$ & 4 & 25.0 & 12 & 75.0 & \\
\hline $13-24$ & 9 & 14.1 & 55 & 85.9 & \\
\hline $25-32$ & 25 & 39.7 & 38 & 60.3 & 0.009 \\
\hline \multicolumn{6}{|l|}{ Stage } \\
\hline $\mid-\|$ & 22 & 26.5 & 61 & 73.5 & \\
\hline||$|-| V$ & 19 & 25.0 & 57 & 75.0 & 0.858 \\
\hline \multicolumn{6}{|l|}{ T-class } \\
\hline Tis-T2 & 30 & 30.0 & 70 & 70.0 & \\
\hline T3-T4 & 11 & 18.6 & 48 & 81.4 & 0.135 \\
\hline \multicolumn{6}{|l|}{ Lymph node status } \\
\hline No & 28 & 24.1 & 88 & 75.9 & \\
\hline N1 or more & 13 & 30.2 & 30 & 69.8 & 0.541 \\
\hline \multicolumn{6}{|l|}{ Site } \\
\hline Tongue & 20 & 28.6 & 50 & 71.4 & \\
\hline Gum or palate & 11 & 20.4 & 43 & 79.6 & \\
\hline Floor of the mouth & 9 & 36.0 & 16 & 64.0 & \\
\hline Cheek & 1 & 10.0 & 9 & 90.0 & 0.313 \\
\hline
\end{tabular}

Statistically significant values are in bold

Table 7 Logistic Regression analysis of the CRP/alb in 159 oral carcinoma patients

\begin{tabular}{|c|c|c|c|c|c|c|c|c|}
\hline & \multicolumn{4}{|c|}{ Univariate } & \multicolumn{4}{|c|}{ Multiple } \\
\hline & \multicolumn{4}{|c|}{$>0.05$ of CRP/Alb before treatment } & \multicolumn{4}{|c|}{$>0.05$ of CRP/Alb before treatment } \\
\hline & \multirow[b]{2}{*}{ OR } & \multicolumn{2}{|c|}{$95 \%$ Cl for OR } & \multirow[b]{2}{*}{$p$ value } & \multirow[b]{2}{*}{ OR } & \multicolumn{2}{|c|}{$95 \%$ Cl for OR } & \multirow[b]{2}{*}{$p$ value } \\
\hline & & Lower & Upper & & & Lower & Upper & \\
\hline \multicolumn{9}{|l|}{ Heavy alcohol use (yes f.) } \\
\hline no heavy alcohol use & 0.181 & 0.041 & 0.802 & 0.024 & 0.114 & 0.024 & 0.541 & 0.006 \\
\hline \multicolumn{9}{|c|}{ Charlson Comorbidity Index ( $\geq 5$ f.) } \\
\hline $0-1$ & 0.050 & 0.006 & 0.418 & 0.006 & 0.033 & 0.004 & 0.284 & 0.002 \\
\hline $2-4$ & 0.171 & 0.022 & 1.339 & 0.093 & 0.143 & 0.018 & 1.130 & 0.065 \\
\hline \multicolumn{9}{|c|}{ Total number of teeth ( 0 f.) } \\
\hline $1-12$ & 0.692 & 0.128 & 3.752 & 0.670 & & & & \\
\hline $13-24$ & 1.410 & 0.334 & 5.950 & 0.640 & & & & \\
\hline $25-32$ & 0.351 & 0.091 & 1.357 & 0.129 & & & & \\
\hline
\end{tabular}

Statistically significant values are in bold 
comorbidity combination of age and disease history and heavy alcohol use increased the CRP/alb ratio in OSCC patients independently. Consideration of these predictive variables are warranted when assessing early postoperative prognosis of a patient with OSCC.

\section{Abbreviations}

alb: albumin; CRP: C-reactive protein; CRP/alb: C-reactive protein to albumin; CCl: Charlson Comorbidity Index; Cl: confidence interval; hs-CRP: highsensitivity-CRP; IL: interleukin; MEWS: modified early warning score; OSCC: oral squamous cell carcinoma; TNM: tumour, node, and metastasis.

\section{Acknowledgements}

Not applicable.

\section{Authors' contributions}

AK: Data curation, formal analysis, investigation, visualization, writing —original draft. JU: Conceptualization, methodology, project administration, supervision, writing — review and editing. MM-G: Investigation, methodology, writingreview and editing. SK: writing — review and editing. JS:Conceptualization, formal analysis, methodology, project administration, supervision, validation, writing - review and editing. All authors read and approved the final manuscript.

\section{Funding}

The Helsinki University Hospital Research Fund financially supported A.K., J.U., S.K., and J.S.

\section{Availability of data and materials}

The datasets used and/or analysed during the current study are available from the corresponding author on reasonable request.

\section{Declarations}

\section{Ethical approval and consent to participate}

This article does not contain any studies with human participants or animals performed by any of the authors. The study was approved by the Internal Review Board of the Head and Neck Centre, Helsinki University Central Hospital, Finland (HUS/66/2018). The Internal Review Board of the Head and Neck Centre waived the requirement of informed consent due to the retrospective nature of this study. The guidelines of the Declaration of Helsinki were followed in this study.

\section{Consent for publication}

Not applicable.

\section{Conflict of interest}

The authors declare that they have no competing interests.

\section{Author details}

${ }^{1}$ Department of Oral and Maxillofacial Diseases, University of Helsinki and Helsinki University Hospital, P.O. Box 220, 00029 Helsinki, Finland. ${ }^{2}$ HUS Radiology (Medical Imaging Center), Helsinki, Finland. ${ }^{3}$ Finnish Student Health Service, Helsinki, Finland.

Received: 11 December 2020 Accepted: 9 March 2021

Published online: 19 March 2021

\section{References}

1. Ferlay J, Soerjomataram I, Dikshit R, Eser S, Mathers C, Rebelo M, Parkin DM, Forman D, Bray F. Cancer incidence and mortality worldwide: sources, methods and major patterns in GLOBOCAN 2012. Int J Cancer. 2015;136(5):359-86. https://doi.org/10.1002/ijc.29210.

2. World Health Organization, International Agency For Research On Cancer. Tobacco smoking and involuntary smoking. IARC monographs on the evaluation of carcinogenic risk of chemicals to humans. 83. Lyon (France): IARC; 2004.

3. Galvão-Moreira LV, da Cruz MCFN. Screening and early detection of oral cancer: current controversies. Acta Odontol Scand. 2017;75:361-5. https:// doi.org/10.1080/00016357.2017.1316868.

4. Boeve K, Melchers LJ, Schuuring E, Roodenburg JL, Halmos GB, van Dijk BA, van der Vegt B, Witjes MJ. Addition of tumour infiltration depth and extranodal extension improves the prognostic value of the pathological TNM classification for early-stage oral squamous cell carcinoma. Histopathology. 2019;75(3):329-37. https://doi.org/10.1111/his.13886.

5. Coussens LM, Werb Z. Inflammation and cancer. Nature. 2002;420(6917):860-7. https://doi.org/10.1038/nature01322.

6. Jeng JH, Wang YJ, Chiang BL, Lee PH, Chan CP, Ho YS, Wang TM, Lee JJ, Hahn $\sqcup$, Chang MC. Roles of keratinocyte inflammation in oral cancer: regulating the prostaglandin E2, interleukin- 6 and TNF-alpha production of oral epithelial cells by areca nut extract and arecoline. Carcinogenesis. 2003;24(8):1301-15. https://doi.org/10.1093/carcin/bgg083.

7. Park HC, Kim MY, Kim CH. C-reactive protein/albumin ratio as prognostic score in oral squamous cell carcinoma. J Korean Assoc Oral Maxillofac Surg. 2016;42(5):243-50. https://doi.org/10.5125/jkaoms.2016.42.5.243.

8. Tai SF, Chien HT, Young CK, Tsao CK, de Pablo A, Fan KH, Liao CT, Wang HM, Kang CJ, Chang JT, Huang SF. Roles of preoperative C-reactive protein are more relevant in buccal cancer than other subsites. World J Surg Oncol. 2017;15(1):47. https://doi.org/10.1186/s12957-017-1116-5.

9. Alberici Pastore C, Paiva Orlandi S, González MC. Association between an inflammatory-nutritional index and nutritional status in cancer patients. Nutr Hosp. 2013;28(1):188-93. https://doi.org/10.3305/nh.2013.28.1.6167.

10. Gupta D, Lis CG. Pretreatment serum albumin as a predictor of cancer survival: a systematic review of the epidemiological literature. Nutr J. 2010;9:69. https://doi.org/10.1186/1475-2891-9-69.

11. Roxburgh CS, McMillan DC. Cancer and systemic inflammation: treat the tumour and treat the host. Br J Cancer. 2014;110(6):1409-12. https://doi.org/ 10.1038/bjc.2014.90.

12. Metgud R, Patel S. Serum and salivary levels of albumin as diagnostic tools for oral pre-malignancy and oral malignancy. Biotech Histochem. 2014:89(1):8-13. https://doi.org/10.3109/10520295.2013.793394.

13. Al-Subaie N, Reynolds T, Myers A, Sunderland R, Rhodes A, Grounds RM, Hall GM. C-reactive protein as a predictor of outcome after discharge from the intensive care: a prospective observational study. Br J Anaesth. 2010;105(3):318-25. https://doi.org/10.1093/bja/aeq171.

14. Fairclough E, Cairns E, Hamilton J, Kelly C. Evaluation of a modified early warning system for acute medical admissions and comparison with C-reactive protein/albumin ratio as a predictor of patient outcome. Clin Med (Lond). 2009;9(1):30-3. https://doi.org/10.7861/clinmedicine.9-1-30.

15. Wei XL, Wang FH, Zhang DS, Qiu MZ, Ren C, Jin Y, Zhou YX, Wang DS, He MM, Bai L, Wang F, Luo HY, Li YH, Xu RH. A novel inflammation-based prognostic score in esophageal squamous cell carcinoma: the C-reactive protein/albumin ratio. BMC Cancer. 2015;15:350. https://doi.org/10.1186/ s12885-015-1379-6.

16. Kinoshita A, Onoda H, Imai N, Iwaku A, Oishi M, Tanaka K, Fushiya N, Koike $\mathrm{K}$, Nishino H, Matsushima M. The C-reactive protein/albumin ratio, a novel inflammation-based prognostic score, predicts outcomes in patients with hepatocellular carcinoma. Ann Surg Oncol. 2015;22(3):803-10. https://doi. org/10.1245/s10434-014-4048-0.

17. Zhou T, Zhan J, Hong S, Hu Z, Fang W, Qin T, Ma Y, Yang Y, He X, Zhao Y, Huang Y, Zhao H, Zhang L. Ratio of C-reactive protein/albumin is an inflammatory prognostic score for predicting overall survival of patients with small-cell lung cancer. Sci Rep. 2015;5:10481. https://doi.org/10.1038/srep1 0481.

18. Yue H, Xu X, Liu Q, Li X, Xiao Y, Hu B. Effects of non-surgical periodontal therapy on systemic inflammation and metabolic markers in patients undergoing haemodialysis and/or peritoneal dialysis: a systematic review and meta-analysis. BMC Oral Health. 2020;20(1):18. https://doi.org/10.1186/ s12903-020-1004-1.

19. Cholewa M, Madziarska K, Radwan-Oczko M. The association between periodontal conditions, inflammation, nutritional status and calciumphosphate metabolism disorders in hemodialysis patients. J Appl Oral Sci. 2018;26:e20170495. https://doi.org/10.1590/1678-7757-2017-0495.

20. Kshirsagar AV, Craig RG, Beck JD, Moss K, Offenbacher S, Kotanko P, Yoshino M, Levin NW, Yip JK, Almas K, Lupovici E, Falk RJ. Severe periodontitis is associated with low serum albumin among patients on maintenance 
hemodialysis therapy. Clin J Am Soc Nephrol. 2007;2(2):239-44. https://doi. org/10.2215/CJN.02420706.

21. Corbella S, Veronesi P, Galimberti V, Weinstein R, Del Fabbro M, Francetti $\mathrm{L}$. Is periodontitis a risk indicator for cancer? A meta-analysis. PLOS ONE. 2018;13:e0195683. https://doi.org/10.1371/journal.pone.0195683.

22. Ahn J, Segers S, Hayes RB. Periodontal disease, Porphyromonas gingivalis serum antibody levels and orodigestive cancer mortality. Carcinogenesis. 2012;33(5):1055-8. https://doi.org/10.1093/carcin/bgs112.

23. Moideen S. TNM Staging of Lip and Oral Cavity cancers - AJCC 8th Edition. 2018;2019.

24. Quan H, Li B, Couris CM, Fushimi K, Graham P, Hider P, Januel JM, Sundararajan V. Updating and validating the Charlson comorbidity index and score for risk adjustment in hospital discharge abstracts using data from 6 countries. Am J Epidemiol. 2011;173(6):676-82. https://doi.org/10.1093/aje/kwq433.

25. Jerjes W, Upile T, Radhi H, Petrie A, Abiola J, Adams A, Kafas P, Callear J, Carbiner R, Rajaram K, Hopper C. The effect of tobacco and alcohol and their reduction/cessation on mortality in oral cancer patients: short communication. Head Neck Oncol. 2012;4:6. https://doi.org/10.1186/1758-3284-4-6.

26. Treatment of alcohol abuse. Working group appointed by the Finnish Medical Society Duodecim and the Finnish Society of Addiction Medicine Current Care Guidelines. Helsinki: The Finnish Medical Society Duodecim, 2018. Available online at: www.kaypahoito.fi. Accessed 11 October 2020

27. Keinänen A, Marinescu-Gava M, Uittamo J, Hagström J, Marttila E, Snäll J. Periodontitis in tonsil cancer patients-A comparative study in accordance with tumour p16 status. Oral Dis. 2020. https://doi.org/10.1111/odi.13437.

28. Wang Q, Song X, Zhao Y, He Q, Shi M, XU P, Ni S, Chen Y, Lin J, Zhang L. Preoperative high c-reactive protein/albumin ratio is a poor prognostic factor of oral squamous cell carcinoma. Future Oncol. 2019;15(19):2277-86 https://doi.org/10.2217/fon-2019-0063.

29. Salas S, Deville JL, Giorgi R, et al. Nutritional factors as predictors of response to radio-chemotherapy and survival in unresectable squamous head and neck carcinoma. Radiother Oncol. 2008;87(2):195-200. https://doi.org/10. 1016/j.radonc.2008.02.011.

30. Xu H, Hu L, Wei X, Niu J, Gao Y, He J, Hou J. The predictive value of preoperative high-sensitive C-reactive protein/albumin ratio in systemic inflammatory response syndrome after percutaneous nephrolithotomy. J Endourol. 2019;33(1):1-8. https://doi.org/10.1089/end.2018.0632.
31. Gallus S, Lugo A, Suatoni P, Taverna F, Bertocchi E, Boffi R, Marchiano A, Morelli D, Pastorino U. Effect of tobacco smoking cessation on C-reactive protein levels in a cohort of low-dose computed tomography screening participants. Sci Rep. 2018;8(1):12908. https://doi.org/10.1038/ s41598-018-29867-9.

32. Imhof A, Froehlich M, Brenner $H$, Boeing H, Pepys MB, Koenig W. Effect of alcohol consumption on systemic markers of inflammation. Lancet. 2001;357(9258):763-7. https://doi.org/10.1016/S0140-6736(00)04170-2.

33. Mantovani A, Allavena P. Sica A, Balkwill F. Cancer-related inflammation. Nature. 2008;454(7203):436-44. https://doi.org/10.1038/nature07205.

34. Balkwill F, Mantovani A. Inflammation and cancer: back to Virchow? Lancet. 2001;357(9255):539-45. https://doi.org/10.1016/S0140-6736(00)04046-0.

35. Allavena P, Germano G, Marchesi F, Mantovani A. Chemokines in cancer related inflammation. Exp Cell Res. 2011;317(5):664-73. https://doi.org/10. 1016/j.yexcr.2010.11.013.

36. Amiri Dash Atan N, Koushki M, Rezaei Tavirani M, Ahmadi NA. Protein-protein interaction network analysis of salivary proteomic data in oral cancer cases. Asian Pac J Cancer Prev. 2018;19(6):1639-45. https://doi.org/10. 22034/APJCP.2018.19.6.1639.

37. Goldwasser P, Feldman J. Association of serum albumin and mortality risk. J Clin Epidemiol. 1997;50(6):693-703. https://doi.org/10.1016/s0895-4356(97) 00015-2.

38. Don BR, Kaysen G. Serum albumin: relationship to inflammation and nutrition. Semin Dial. 2004;17(6):432-7. https://doi.org/10.1111/j.0894-0959.2004 17603.X.

39. Nelson JJ, Liao D, Sharrett AR, Folsom AR, Chambless LE, Shahar E, Szklo M, Eckfeldt J, Heiss G. Serum albumin level as a predictor of incident coronary heart disease: the Atherosclerosis Risk in Communities (ARIC) study. Am J Epidemiol. 2000;151(5):468-77. https://doi.org/10.1093/oxfordjournals.aje. a010232.

\section{Publisher's Note}

Springer Nature remains neutral with regard to jurisdictional claims in published maps and institutional affiliations.
Ready to submit your research? Choose BMC and benefit from:

- fast, convenient online submission

- thorough peer review by experienced researchers in your field

- rapid publication on acceptance

- support for research data, including large and complex data types

- gold Open Access which fosters wider collaboration and increased citations

- maximum visibility for your research: over $100 \mathrm{M}$ website views per year

At BMC, research is always in progress.

Learn more biomedcentral.com/submissions 